\title{
Efeito da temperatura e reação de genótipos de quiabeiro ao mofo branco
}

\author{
Ivan Herman Fischer ${ }^{1}$, Mirian de Souza Filetti ${ }^{1}$, Juliana Cristina Sodário Cruz ${ }^{1}$, César Júnior Bueno ${ }^{2}$
}

${ }^{1}$ Polo Regional Centro Oeste / APTA. Avenida Rodrigues Alves, 40-40, 17030-000 Bauru-SP-Brasil, ihfische@apta.sp.gov.br; ${ }^{2}$ Instituto Biológico / APTA. Rodovia Heitor Penteado, Km 03, Jardim das Palmeiras, Caixa Postal 70, 13092-543, Campinas-SP-Brasil

Autor para correspondência: Ivan Herman Fischer (ihfische@apta.sp.gov.br).

Data de chegada: 29/09/2013. Aceito para publicação em: 03/02/2014.

1934

\section{RESUMO}

Fischer, I.H.; Filetti, M.S.; Cruz, J.C.S.; Júnior Bueno, C.. Efeito da temperatura e reação de genótipos de quiabeiro ao mofo branco. Summa Phytopathologica, v.40, n.1, p.49-53, 2014.

O quiabeiro é suscetível a várias doenças que podem causar prejuízos ao agricultor, caso não sejam manejadas. Objetivaram-se avaliar o efeito da temperatura e a reação de genótipos de quiabeiro ao mofo branco. Plantas de 30 dias inoculadas na região do colo, com e sem ferimento, com dois isolados de Sclerotinia sclerotiorum, foram mantidas por duas semanas nas temperaturas de $15 ; 20 ; 25 ; 30$ ou $35^{\circ} \mathrm{C}$. Quatorze genótipos de quiabeiro com um e dois meses de emergência, assim como frutos no ponto de colheita comercial tiveram seus comportamentos avaliados quanto à doença. Avaliaram-se a incidência de plantas com tombamento ou mortas e o comprimento da lesão nos frutos inoculados.
A doença foi favorecida por temperaturas entre 15 e $20^{\circ} \mathrm{C}$ e, de maneira geral, não foram observadas diferenças entre os isolados e influência do ferimento na ocorrência da doença. Não foram encontrados genótipos de quiabeiro resistentes ao mofo branco, pois todos apresentaram incidência superior a $30 \%$ de plantas mortas, sendo as plantas mais novas mais suscetíveis, e comprimento de lesão nos frutos $\geq 6,0 \mathrm{~cm}$. Entretanto, diferenças de suscetibilidade entre os genótipos foram observadas em plantas de 30 e de 60 dias e podem ser informações úteis aos produtores para escolha de cultivares em clima ameno, assim como ser exploradas em programas de melhoramento.

Palavras-chave adicionais: Abelmoschus esculentus, Sclerotinia sclerotiorum, suscetibilidade

\section{ABSTRACT}

Fischer, I.H.; Filetti, M.S.; Cruz, J.C.S.; Júnior Bueno, C.. Effect of temperature and reaction of okra genotypes to white mold. Summa Phytopathologica, v.40, n.1, p.49-53, 2014.

The okra plant is susceptible to several diseases that can cause losses to the farmer if not managed. This study aimed to evaluate the effect of temperature and the reaction of okra genotypes to white mold. Plants aged 30 days, inoculated in the collar region, injured or not, including two strains of Sclerotinia sclerotiorum, were maintained for two weeks at temperatures of 15, 20, 25,30 or $35^{\circ} \mathrm{C}$. Fourteen okra genotypes at one and two months after emergence, as well as fruits at commercial harvest time, had their behavior evaluated for the disease. Damping-off or dead plants were evaluated, as well as the injure length in the inoculated fruits. The disease was favored by temperatures between 15 and $20^{\circ} \mathrm{C}$ and, in general, no differences were observed between the isolates and the influence of the injury on the disease occurrence. There were no okra genotypes resistant to white mold, since all of them had more than $30 \%$ of incidence of dead plants; younger plants were more susceptible and the injure length in fruits was $\geq$ $6.0 \mathrm{~cm}$. However, differences in the susceptibility between genotypes were observed for plants aged 30 and 60 days, which could constitute useful information for producers in the choice of cultivars under moderate climate and could be explored in breeding programs.

Additional keywords: Abelmoschus esculentus, Sclerotinia sclerotiorum, susceptibility

O quiabeiro (Abelmoschus esculentus L.) é uma planta da família das Malváceas muito popular em regiões de clima tropical e subtropical e com características agronômicas peculiares à agricultura familiar. Possui alto valor alimentício, ciclo vegetativo rápido, fácil cultivo e alta rentabilidade e, devido as suas utilidades, tem sofrido um crescente aumento de consumo (12).

A cultura do quiabeiro pode ser atacada por pragas e doenças, sendo que as doenças mais comuns são causadas por fungos. O mofo branco é causado por Sclerotinia sclerotiorum (Lib.) de Bary, um patógeno polífago que afeta pelo menos 408 espécies e 278 gêneros de plantas, inclusive o quiabeiro (2). É um patógeno comumente associado a perdas significativas de rendimento em lavouras de feijão e soja, com relatos no Brasil de perdas de $80 \%$ (18) e $100 \%$, respectivamente
(24). Na Flórida, EUA, o mofo branco é considerado uma importante doença no quiabeiro (22). Pode afetar toda a planta, causando lesões necróticas e o apodrecimento do tecido vegetal. Com o avanço dos sintomas, usualmente observam-se sobre o tecido necrosado um crescimento micelial branco cotonoso e escleródios pretos irregulares e de tamanho variável, que podem sobreviver por um longo período no solo dificultando o controle da doença (27).

O mofo branco é um problema sério em diversas culturas, especialmente quando cultivadas em solos contaminados e o clima é frio e úmido (27). Sintomas característicos do ataque de mofo branco em quiabeiro foram observados em uma lavoura comercial do centro oeste paulista, em agosto de 2011, e o agente causal foi confirmado em laboratório com base em suas características morfológicas (21). Até 
o momento não há relatos técnico-científicos de danos em lavouras comerciais de quiabo no Brasil e informações científicas sobre o patossistema mofo branco em quiabeiro. Por exemplo, hoje não se sabe o nível de resistência das variedades de quiabeiro em relação ao patógeno. Portanto, as informações do patossistema serão úteis para definir estratégias de manejo da doença.

$\mathrm{O}$ emprego de variedades geneticamente resistentes constitui o método ideal de controle, por ser aplicável em grandes áreas e possuir baixo impacto ambiental comparado aos agrotóxicos (3). As variedades de quiabeiro podem ser classificadas de acordo com o porte, tamanho do fruto, cor do fruto fresco e secção do fruto. A variedade Santa Cruz-47 é uma das mais plantadas no Brasil. Apresenta estatura média, folhas com limbo bem recortado, frutos longos, roliços, lisos e de cor verdebrilhante e resistência à murcha verticilar (Verticillium dahliae Kleb.) (12). Resistência ao vírus do mosaico do quiabeiro (Okra yellow vein mosaic virus), outra importante doença da cultura, foi incorporada em uma população desenvolvida pelo Instituto Agronômico de Campinas (IAC), sendo extraídas progênies e obtendo-se seis seleções consideradas elites (25).

Em função da carência de informações, objetivou-se avaliar a reação de 14 genótipos de quiabeiro ao mofo branco e, também, influências de temperatura, ferimento e idade da planta no patossistema.

\section{MATERIAL E MÉTODOS}

Dois isolados de $S$. sclerotiorum foram obtidos por isolamento em meio de cultura batata-dextrose-ágar (BDA) de fragmentos de fruto e de haste de quiabeiro Santa Cruz 47 (Horticeres Sementes) com sintomas de mofo branco, oriundos de plantas cultivadas em lavoura comercial afetada em Arealva-SP (latitude $22^{\circ} 02^{\prime}$ '90" S e longitude $48^{\circ} 90^{\prime} 81$ ' W).

Plantas de quiabeiro Santa Cruz 47 (Horticeres Sementes) foram cultivadas em vasos de 3 litros, contendo substrato Plantmax HT $^{\circledR}$, em casa de vegetação localizada na APTA Centro Oeste Bauru. Após um mês da emergência, as plantas foram inoculadas isoladamente com um disco de micélio dos isolados (Haste e Fruto) de S. sclerotiorum, cultivados por sete dias em BDA, sob temperatura de $25^{\circ} \mathrm{C}$ e fotoperíodo de 12 horas, fixando-se o disco de micélio com uma fita adesiva no colo da planta a uma altura aproximada de $2 \mathrm{~cm}$ do nível do substrato. Avaliou-se também a inoculação sem e com ferimento, inserindo-se $0,3 \mathrm{~cm}$ de uma agulha histológica no colo da planta, previamente a deposição do disco de micélio. Discos apenas com meio de cultura, sem o patógeno, foram colocados, respectivamente, nos ferimentos e nos tecidos intactos da base do caule, nas plantas controle.

As plantas inoculadas foram mantidas em BOD por duas semanas nas temperaturas de $15 ; 20 ; 25 ; 30$ ou $35^{\circ} \mathrm{C}$ sob fotoperíodo de 12 horas e irrigadas diariamente, sendo que nas primeiras 48 horas foram mantidas em câmara úmida, obtida pelo envolvimento das plantas previamente irrigadas por saco plástico transparente. A incidência (\%) de plantas sintomáticas, caracterizada pelo tombamento da planta em função do apodrecimento da região do colo, foi avaliada aos sete e quatorze dias após a inoculação. $\mathrm{O}$ experimento foi repetido uma vez.

$\mathrm{O}$ delineamento experimental foi o inteiramente casualizado em esquema fatorial $5 \times 2 \times 2$, sendo cinco temperaturas, dois isolados do patógeno e duas metodologias de inoculação, adotando-se seis plantas por tratamento e a repetição representada por uma planta. Os dados de incidência do mofo branco em função da temperatura foram analisados por regressão polinomial e os tratamentos em cada temperatura submetidos à análise de variância, com as médias comparadas pelo
Teste de Scott-Knott a 5\% de probabilidade.

Após definição da temperatura mais favorável ao patossistema em estudo $\left(15^{\circ} \mathrm{C}\right)$, assim como a necessidade ou não de ferimento na inoculação, quatorze genótipos de quiabeiro tiveram seu comportamento avaliados quanto ao mofo branco, sendo seis seleções do programa de melhoramento do IAC $(8.1,20.1 \mathrm{R}, 47.1,13.1 .1,13.1 .2$ e 20.1.2), três cultivares da empresa Isla (Amarelinho, Clemson Americano 80 e Santa Cruz 47), duas da Sakata Seed Sudamerica (Colhe Bem e Santa Cruz 47), uma da Eagle (Xingó), da Horticeres Sementes (Santa Cruz 47) e da Topseed (Santa Cruz 47).

As plantas dos 14 genótipos de quiabeiro foram cultivadas conforme descrito no ensaio anterior. A inoculação dos dois isolados do patógeno foi realizada em plantas com um e dois meses de emergência, pela deposição de um disco de micélio no colo das plantas, sem ferimento. As plantas permaneceram as primeiras 48 horas a $15^{\circ} \mathrm{C}$, fotoperíodo de 12 horas e $90-95 \%$ de umidade relativa, em câmara com temperatura e umidade relativa controladas, visando favorecer o processo infeccioso. Em seguida, retornaram a casa de vegetação, com irrigação diária por gotejamento (microtubos) e foram avaliadas aos sete e quatorze dias após a inoculação quanto à incidência dos sintomas de mofo branco. $\mathrm{O}$ comportamento dos genótipos de quiabeiro foi avaliado no inverno de 2012 e repetido no mesmo período de 2013. A temperatura máxima da casa de vegetação foi regulada para $28,0^{\circ} \mathrm{C}$, sendo a temperatura média, nas duas semanas após a inoculação, de $21,3^{\circ} \mathrm{C}$ e a mínima de $11,8^{\circ} \mathrm{C}$.

Frutos de quiabeiro dos 14 genótipos cultivados em casa de vegetação foram coletados no ponto de colheita comercial quando estavam tenros, pré-selecionados para ausência de defeitos e higienizados, mantendo-os em solução de hipoclorito de sódio $0,5 \%$ por 2 minutos e, posteriormente, lavados com água corrente para retirar o excesso do produto. $\mathrm{Na}$ sequência, os frutos foram secos em temperatura ambiente e acondicionados em bandejas plásticas higienizadas, quatro frutos por bandeja. A inoculação dos isolados foi feita separadamente pela fixação com fita adesiva de um disco de micélio na porção mediana de cada fruto. Os frutos foram mantidos a $15^{\circ} \mathrm{C}$ e $80 \%$ de umidade relativa em câmara, sendo que nas primeiras 48 horas o processo infeccioso foi favorecido pela manutenção dos frutos em câmara úmida, obtida pelo envolvimento das bandejas por saco plástico contendo algodão umedecido no seu interior. Após quatro dias da inoculação, avaliou-se a severidade, expressa pela medida do comprimento da lesão obtida com régua milimetrada. O experimento foi repetido uma vez.

O delineamento experimental para os ensaios com os genótipos foi o inteiramente casualizado em esquema fatorial 14 x 2 (14 genótipos e dois isolados do patógeno), adotando-se seis plantas e quatro frutos por genótipo, sendo cada planta ou fruto uma repetição. Para os dados de incidência de plantas doentes e de severidade nos frutos em relação aos genótipos, as médias foram comparadas pelo Teste de Scott-Knott a $5 \%$ de probabilidade.

\section{RESULTADOS E DISCUSSÃO}

A ocorrência do mofo branco do quiabeiro foi favorecida por temperaturas mais amenas, entre 15 e $20^{\circ} \mathrm{C}$, apresentando $100 \%$ de incidência a $15^{\circ} \mathrm{C}$ para os dois isolados do patógeno, independente da inoculação ter sido realizada com ou sem ferimento (Figura 1), em contraste com as plantas utilizadas como controle, que não mostraram sintomas. Sintomas de descoloração do colo das plantas, próximo da região de inoculação, e início de tombamento foram observados a partir do quarto dia da inoculação. Das plantas sintomáticas (mortas), 88\% 
foram observadas já aos sete dias após a inoculação, evidenciando a agressividade do patógeno, e os $12 \%$ restantes, na segunda semana de avaliação. Em estudo da gama de plantas hospedeiras do patógeno, quiabeiros com 14 dias de idade, inoculados com S. sclerotiorum isolado de algodão, apresentaram 100\% de mortalidade após sete dias da inoculação, realizada com ou sem ferimento na base do caule a exemplo do presente trabalho (7).

Ausência de sintomas foi observada a partir da temperatura de $30^{\circ} \mathrm{C}$ na inoculação do isolado Haste com ferimento e na temperatura de $35^{\circ} \mathrm{C}$ não houve ocorrência de mortes para ambos isolados do patógeno e metodologias de inoculação (Figura 1). Os dados de incidência do mofo branco em função da temperatura ajustaram-se significativamente para as equações lineares, com $\mathrm{R}^{2}$ superior a 0,80 . Segundo Reis \& Lopes (27), a temperatura ótima para a ocorrência do mofo branco está entre 15 e $21^{\circ} \mathrm{C}$. Ausência de sintomas do mofo branco na temperatura de $30^{\circ} \mathrm{C}$ havia sido relatada em plantas de soja (29). De maneira geral não foram observadas diferenças significativas nas temperaturas avaliadas entre os isolados, assim como entre a inoculação com ou sem ferimento na ocorrência da doença, exceto na temperatura de $20^{\circ} \mathrm{C}$ entre os isolados na inoculação com ferimento (isolado Fruto $=50 \%$ de incidência $\mathrm{x}$ isolado Haste $=100 \%$ ).

Por ser considerada uma planta tolerante ao calor e buscando-se um ambiente desfavorável a ocorrência do mofo branco, recomenda-se o cultivo do quiabeiro em regiões tropicais do Brasil, onde as temperaturas médias são superiores a $20^{\circ} \mathrm{C}(15)$. As temperaturas médias apropriadas ao cultivo do quiabeiro estão na faixa de 21,1 a $29,4^{\circ} \mathrm{C}$, com a média das mínimas em $18,3^{\circ} \mathrm{C}(11)$, comumente encontrada nas regiões subtropicais do país, como nos estados do sudeste. Para estas regiões recomenda-se, em áreas com histórico do mofo branco, a exploração desta cultura apenas no verão, como forma de minimizar possíveis problemas com a doença.

Não foram encontrados genótipos de quiabeiro resistentes ao mofo branco, pois todos apresentaram incidência superior a 30\% de plantas mortas. Entretanto, diferenças de suscetibilidade entre os genótipos foram observadas em plantas de 30 e de 60 dias, com os genótipos divididos em dois grupos de suscetibilidade (Tabela 1). Das plantas sintomáticas, 84 e $88 \%$ foram observadas a partir da primeira semana da inoculação, em plantas de 30 e de 60 dias, respectivamente.

Uma vez que não foram observadas diferenças entre os dois isolados do patógeno $(\mathrm{p}=0,210)$, assim como não teve interação genótipos $\mathrm{x}$ isolados $(\mathrm{p}=0,823)$, utilizou-se a média dos isolados na comparação dos genótipos de quiabeiro. Entretanto, diferenças de agressividade foram observadas em soja entre isolados do patógeno obtidos de hospedeiros diferentes e de regiões diferentes (28), preconizando-se estudos com um número significativo de isolados em programas de melhoramento. Em feijoeiro, houve diferença significativa entre as 13 cultivares e entre os seis isolados do patógeno, entretanto, não foi observada interação cultivares x isolado (5). Em plantas de 30 dias, oito genótipos estatisticamente semelhantes apresentaram incidência média entre 33,3 e 62,5\%, enquanto outros seis genótipos, considerados mais suscetíveis, apresentaram incidência entre 66,7 e 100\%. Já em plantas de 60 dias, quatro genótipos foram considerados menos suscetíveis, com incidências entre 4,2 e 8,4, diferindo significativamente dos demais 10 genótipos, com incidências entre 12,5 e 29,2 (Tabela 1).

Interação significativa foi observada entre genótipos $\mathrm{x}$ idade das plantas $(\mathrm{p}=0,001)$, ou seja, alguns genótipos classificados como mais suscetíveis aos 30 dias, foram classificados como menos suscetíveis aos 60 dias, como é o caso dos genótipos Xingó e Clemson Americano, assim como alguns classificados como menos suscetíveis aos 30 dias foram mais suscetíveis aos 60 dias, como ocorreu com Santa Cruz 47 (Isla e Sakata), 20.1.2, 8.1, 47.1 (IAC) e Amarelinho. Dentre os genótipos avaliados, destacam-se os genótipos Colhe bem e Santa Cruz 47 (Topseed) com as menores incidências aos 30 e 60 dias. Considerável variabilidade para algumas características físicas, químicas e minerais foram encontradas em cultivares de quiabo (23), as quais podem estar relacionadas a diferenças na suscetibilidade a doenças.

A suscetibilidade foi maior nas plantas mais novas $(p=0,0001)$, atingindo uma média superior a $60 \%$ de plantas mortas, enquanto a incidência nas plantas mais velhas foi inferior a $20 \%$ na média, sugerindo o efeito de "resistência de planta adulta". Chun et al. (9) estudaram o efeito da idade da planta em caules destacados de plantas de soja com idades entre três e sete semanas e concluíram que o comprimento de lesão do mofo branco tende a diminuir com a maturidade. A título de manejo e em hipótese, sugere-se que no período mais frio do ano, as

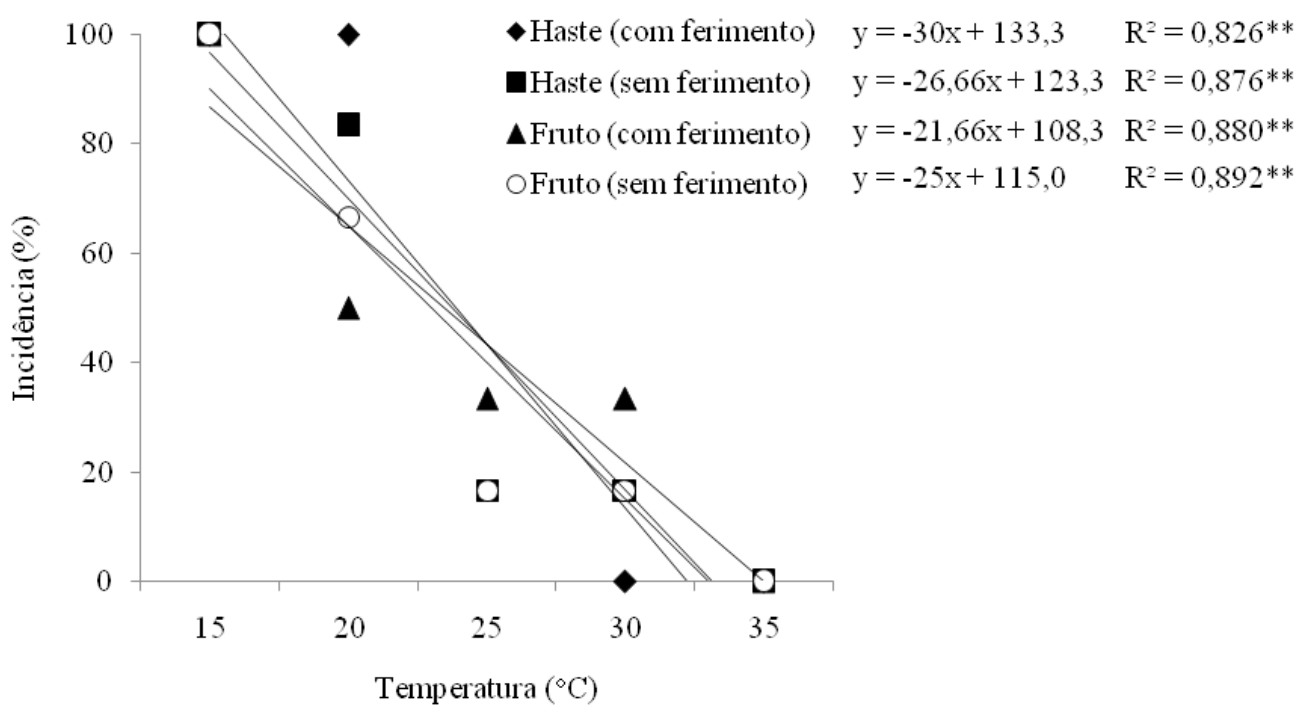

Figura 1. Incidência (\%) de mofo branco do quiabeiro, após duas semanas da inoculação de dois isolados do patógeno Sclerotinia sclerotiorum (Haste e Fruto), com ou sem ferimento no colo, em plantas submetidas a diferentes temperaturas. ${ }^{* *}$ significativo a $1 \%$. 
plantas estejam adultas para haver menor suscetibilidade das mesmas ao patógeno em condições climáticas favoráveis.

Diferentemente do observado nas inoculações no colo das plantas, não foram observas diferenças significativas entre os genótipos de quiabeiro nas inoculações nos frutos $(\mathrm{p}=0,9005)$, assim como entre os isolados de $S$. sclerotiorum $(\mathrm{p}=0,4336)$, com uma média de comprimento de lesão de $6,5 \mathrm{~cm}$, quatro dias após a inoculação do patógeno. Na ausência de interação genótipos $\mathrm{x}$ isolados $(\mathrm{p}=0,602)$, utilizou-se a média dos isolados na comparação dos genótipos de quiabeiro (Tabela 2). Após dois dias da inoculação foram observados sintomas de encharcamento do tecido vegetal ao redor do local da inoculação.

Alguns trabalhos de resistência genética de soja à S. sclerotiorum foram realizados em condições de laboratório, casa de vegetação e campo $(1,8,13,27,30)$, sendo observadas repostas que variam desde elevada resistência até completa suscetibilidade. Resistência parcial foi observada em genótipos de girassol (14), feijão (4), ervilha (26) e amendoim (10), entretanto, a resistência completa ainda não foi relatada em condições de campo. O controle genético do mofo branco é considerado quantitativo e altamente influenciável pelo ambiente e fatores como idade e arquitetura da planta $(4,6,19)$. De maneira geral, a variação genética de resistência à doença é limitada nos germoplasmas comerciais e o melhoramento para resistência é difícil, em parte pela baixa correlação entre o campo e testes laboratoriais de resistência e devido à resistência de campo muitas vezes ser devido às características anatômicas da planta em evitar a doença ao invés de resistência fisiológica $(1,16,17)$. Contudo, a maioria dos mecanismos de escape associados ao mofo branco apresenta alta herdabilidade e são prontamente avaliados em campo. Assim, a associação entre a resistência fisiológica e mecanismos de escape morfológicos constituem

Tabela 1. Incidência (\%) de plantas com mofo branco em diferentes genótipos de quiabeiro, após inoculação com isolados de Sclerotinia sclerotiorum (Fruto e Haste), aos 30 e 60 dias após a semeadura ${ }^{1}$.

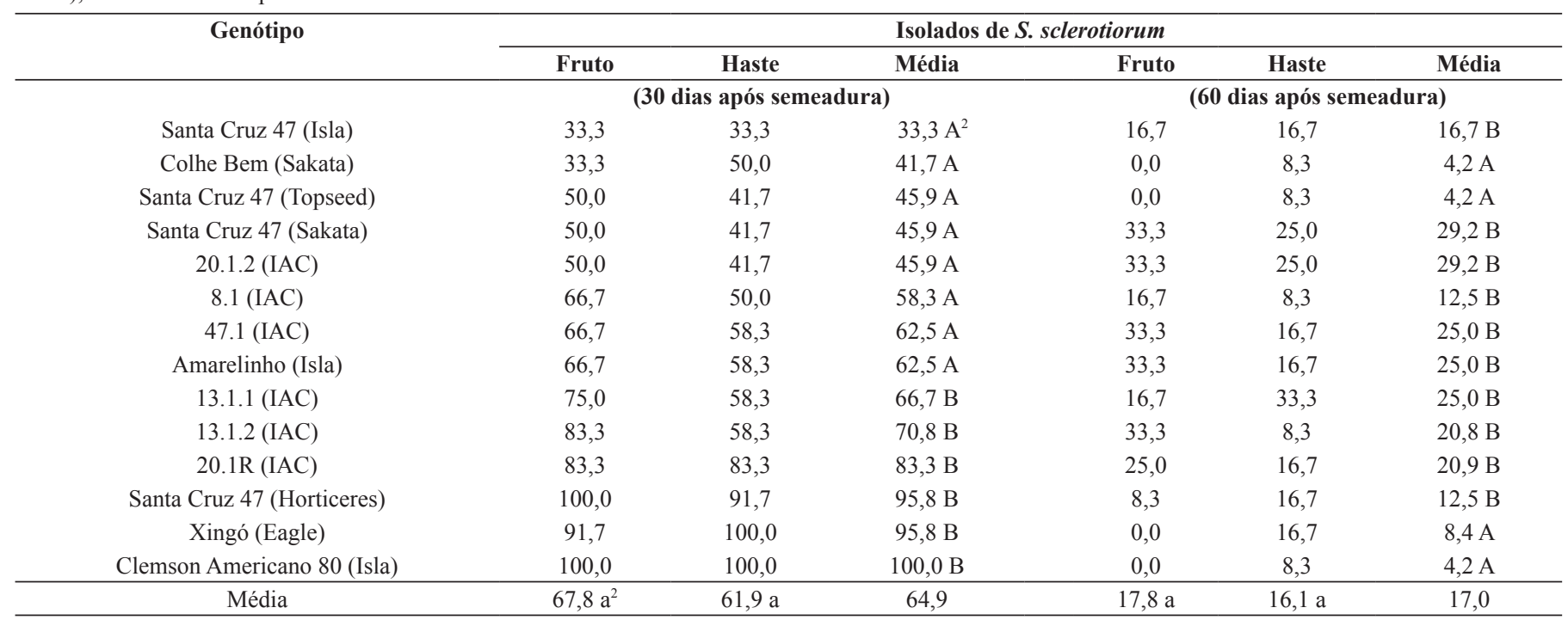

${ }^{1}$ Média de dois experimentos com seis plantas/genótipo cada.

${ }^{2}$ Dados seguidos pela mesma letra minúscula na linha e maiúscula na coluna não diferem entre si, ao nível de 5\%, pelo teste de Scott-Knott. Análise estatística com os dados originais transformados em raiz $\mathrm{x}+0,5$. $\mathrm{CV} \%=30,26$.

Tabela 2. Comprimento de lesão $(\mathrm{cm})$ do mofo branco em quiabos armazenados a $15^{\circ} \mathrm{C}$, após quatro dias da inoculação com os isolados de Sclerotinia sclerotiorum ${ }^{1}$.

\begin{tabular}{|c|c|c|c|}
\hline \multirow[t]{2}{*}{ Genótipo } & \multicolumn{3}{|c|}{ Isolado de $S$. sclerotiorum } \\
\hline & Fruto & Haste & Média \\
\hline Santa Cruz 47 (Isla) & 6,3 & 6,1 & $6,2 \mathrm{~A}^{2}$ \\
\hline Colhe Bem (Sakata) & 6,8 & 6,1 & $6,5 \mathrm{~A}$ \\
\hline Santa Cruz 47 (Topseed) & 5,8 & 6,0 & $5,9 \mathrm{~A}$ \\
\hline Santa Cruz 47 (Sakata) & 7,5 & 7,2 & $7,4 \mathrm{~A}$ \\
\hline $20.1 .2($ IAC) & 6,1 & 5,8 & $6,0 \mathrm{~A}$ \\
\hline 8.1 (IAC) & 6,4 & 6,4 & $6,4 \mathrm{~A}$ \\
\hline 47.1 (IAC) & 6,9 & 6,6 & $6,8 \mathrm{~A}$ \\
\hline Amarelinho (Isla) & 7,1 & 5,6 & $6,4 \mathrm{~A}$ \\
\hline 13.1.1 (IAC) & 6,1 & 6,1 & $6,1 \mathrm{~A}$ \\
\hline 13.1.2 (IAC) & 6,7 & 6,7 & $6,7 \mathrm{~A}$ \\
\hline $20.1 \mathrm{R}(\mathrm{IAC})$ & 7,0 & 7,3 & $7,2 \mathrm{~A}$ \\
\hline Santa Cruz 47 (Horticeres) & 6,8 & 5,9 & $6,4 \mathrm{~A}$ \\
\hline Xingó (Eagle) & 6,6 & 6,2 & $6,4 \mathrm{~A}$ \\
\hline Clemson Americano 80 (Isla) & 5,7 & 6,1 & $5,9 \mathrm{~A}$ \\
\hline Média & $6,6 \mathrm{a}^{2}$ & $6,3 \mathrm{a}$ & 6,5 \\
\hline
\end{tabular}


uma estratégia viável para a melhoria da planta quanto à resistência ao mofo branco $(19,20)$.

\section{AGRADECIMENTOS}

Os autores agradecem ao Centro de Horticultura do IAC e as empresas Sakata Seed Sudamerica, Isla e Eagle pelo fornecimento das sementes de quiabo.

\section{REFERÊNCIAS BIBLIOGRÁFICAS}

1. Boland, G. J.; Hall, R. Evaluating soybean cultivars for resistance to Sclerotinia sclerotiorum under field conditions. Plant Disease, Saint Paul, v. 71, p. 934-936, 1987.

2. Boland, G. J.; Hall, R. Index of plant hosts of Sclerotinia sclerotiorum. Canadian Journal of Plant Pathology, Guelph, v. 16, p. 93-108, 1994.

3. Camargo, L. E. A. Controle genético. In: Amorim, L.; Rezende, J. A. M.; Bergamin F. A. Manual de fitopatologia: princípio e conceitos. São Paulo: Ceres, 2011. v. 1, cap. 15, p. 325-341.

4. Carneiro, F. F.; Santos, J. B.; Gonçalves, P. R. C.; Antônio, R. P.; Souza, T. P. Genetics of common bean resistance to white mold. Crop Breeding and Applied Biotechnology, Londrina, v. 11, p. 165-173, 2011.

5. Carneiro, F. F.; Zeviani, W. M.; Santos, J. B.; Carvalho, R. S. B.; Alves, F. C.; Dias, J. A. Minimum number of common bean plants per plot to assess field resistance to white mold. Crop Breeding and Applied Biotechnology, Londrina, v. 11, p. 358-364, 2011.

6. Castaño, F.; Vear, F.; Tourvieille, D. Resistance of sunflower inbred lines to various forms of attack by Sclerotinia sclerotiorum and relations with some morphological characters. Euphytica, Wageningen, v. 68, p. 85-98, 1993.

7. Charchar, M. J. D’A.; Anjos, J. R. N.; Ossipi, E. Ocorrência de nova doença do algodoeiro irrigado, no brasil, causada por Sclerotinia sclerotiorum. Pesquisa Agropecuária Brasileira, Brasília, DF, v. 34, n. 6, p. 11011106, 1999.

8. Chaves, M. S.; Martinelli, J. A.; Loch, L. C. Uso de micélio seco de Sclerotinia sclerotiorum como método de inoculação e avaliação da resistência de cultivares de soja. Summa Phytopathologica, Jaguariúna, v. 22, p. 221-224, 1996.

9. Chun, D.; Kao, L. B.; Lockwood, J. L.; Isleib, T. G. Laboratory and field assessment of resistance in soybean to stem rot caused by Sclerotinia sclerotiorum. Plant Disease, Saint Paul, v. 71, p. 811-815, 1987.

10. Cruickshank, A. W.; Cooper, M.; Ryley, M. J. Peanut resistance to Sclerotinia minor and Sclerotinia sclerotiorum. Australian Journal Agricultural Research, Victoria, v. 53, p. 1105-1110, 2002.

11. Ezeakunne, C. O. Large scale fruit and vegetable production in Nigeria. Zaria: Department of Agronomy, Ahmadu Bello University, 1984. 8 p. Short Communication

12. Filgueira, F. A. R. Novo manual de olericultura: agrotecnologia moderna na produção e comercialização de hortaliças. 3. ed. Viçosa: UFV, 2008. 421p.

13. Garcia, R. A.; Juliatti, F. C. Avaliação da resistência da soja a Sclerotinia sclerotiorum em diferentes estádios fenológicos e períodos de exposição ao inóculo. Tropical Plant Pathology, Brasília, DF, v. 37, n. 3, p. 196-
203, 2012.

14. Godoy, M. Sclerotinia resistance in sunflower: genotypic variations of hybrids in three environment of Argentina. Euphytica, Wageningen, v. 145, p. 147-154, 2005.

15. IBGE. Mapa de Clima do Brasil. Rio de Janeiro, 2002.

16. Kim, H. S.; Diers, B. W. Inheritance of parcial resistance to sclerotinia stem rot in soybean. Crop Science, Madison, v. 40, p. 55-61, 2000.

17. Kim, H. S.; Hartman, G. L.; Manandhar, J. B.; Graef, G. L.; Steadman, J. R.; Diers, B. W. Reaction of soybean cultivars to sclerotinia stem rot in Field, greenhouse, and laboratory evaluations. Crop Science, Madison, v. 40, p. 665-669, 2000.

18. Lobo Junior, M.; Nasser, L. C. B. Mofo branco pode limitar o agronegócio da soja, feijão e girassol em áreas infestadas. Informativo Agromen, Orlândia, v. 4, p. 6-8, 2007.

19. Miklas, P. N.; Delorme, R.; Riley, R. Identification of QTL conditioning resistance to white mold in snap bean. Journal American Society Horticultural Science, Palo Alto, v. 128, p. 564-570, 2003.

20. Miklas, P. N.; Hauf, D.; Henson, R.; Grafton, K. F. Inheritance of ICA Bunsiderived resistance in a navy $\times$ pinto bean cross. Crop Science, Madison, v. 44, p. 1584-1588, 2004.

21. Mordue, J. E. M.; Holliday, P. Sclerotinia sclerotiorum (sclerotial state). Kew: CAB, 1976. (CMI. Descriptions of Pathogenic Fungi and Bacteria, n. 513).

22. Mossler, M. A.; Dunn, E. Florida crop pest management profile: Okra. Florida, 2005. Acesso em: 23 set. 2013.

23. Mota, W. F.; Finger, F. L.; Silva, D. J. H.; Corrêa, P. C.; Firme, L. P.; Neves, L. L. M. Caracterização físico-química de frutos de quatro cultivares de quiabo. Horticultura Brasileira, Brasília, DF, v. 23, n. 3, p. 722-725, 2005.

24. Oliveira, V. M.; Santos, F. M.; Bisinoto, F. F.; Hamawaki, O. T. Eficiência de fungicidas no controle da incidência e severidade do mofo branco (Sclerotinia sclerotiurum), na cultura da soja. Enciclopédia Biosfera, Goiânia, v. 7, n. 12, p. 1-7, 2011.

25. Passos, F. A.; Melo, A. M. T.; Azevedo Filho, J. A.; Ribeiro, I. J. A.; Foltran, D. E. Novas seleções IAC de quiabo para o mercado interno e exportação. In: Encontro Sobre Temas de Genética e Melhoramento, 20., 2003, Piracicaba. Anais. Piracicaba: USP, ESALQ, 2003. p. 141.

26. Porter, L. D.; Hoherisel, G.; Coffman, V. A. Resistance of peas to Sclerotinia sclerotiorum in the Pisum core collection. Plant Pathology, Saint Paul, v. 58 , p. 52-60, 2009

27. Reis, A.; Lopes, C. A. Principais fungos de solo em Hortaliças: Epidemiologia e manejo. In: Zambolim, L.; Lopes, C. A.; Picanço, M. C.; Costa, H. (Org.). Manejo integrado de doenças e pragas: hortaliças. Viçosa: Universidade Federal de Viçosa, 2007. p. 189-224.

28- Sagata, E. Métodos de inoculação e avaliação da resistência de genótipos de soja à Sclerotinia sclerotiorum. 2010. 56 f. Dissertação (Mestrado em Agronomia) - Instituto de Ciências Agrárias, Universidade Federal de Uberlândia, Uberlândia.

29. Vuong, T. D.; Hoffman, D. D.; Diers, B. W.; Miller, J. F.; Steadman, J. R.; Hartman, G. L. Evaluation of soybean, dry bean, and sunflower for resistance to Sclerotinia sclerotiorum. Crop Scienci, Madison, v. 44, p. 777-783, 2004

30. Wegulo, S. N.; Yang, X. B.; Martinson, C. A. Soybean cultivar responses to Sclerotinia sclerotiorum in field and controlled environment studies. Plant Disease, Saint Paul, v. 82, p. 1264-1271, 1998. 